\title{
Carbon Emission Efficiency in the Construction Industry and Its Carbon Emission Control Measures: A Case Study of Henan Province, China
}

\author{
Qing jing Shi and Chun Bai† \\ Department of Architecture and Civil Engineering, Shang Qiu University, Shang Qiu 476000, China \\ $\nmid$ Corresponding author: Chun Bai; ansysbc@163.com
}

\section{Nat. Env. \& Poll. Tech. \\ Website: www.neptjournal.com}

Received: 25-02-2020

Accepted: $18-04-2020$

Key Words:

Construction industry; Carbon emission efficiency; Environmental pollution

\begin{abstract}
With the rapid development of urbanization, the Chinese construction industry has generated a large quantity of carbon emission and brought about challenges to sustainable development while making enormous contributions to national economic development. Thus, this industry is the key field of energy conservation and emission reduction. Facilitating sustainable development of the construction industry and scientifically and reasonably evaluating the carbon emission efficiency of the construction industry will be important for effectively controlling carbon emission and boosting the sustainable development of the construction industry. Carbon emission was added into the total-factor productivity model of the traditional construction industry as an environmental factor in this study, and a total-factor evaluation model for the carbon emission efficiency of the construction industry was constructed. Henan Province was taken as an example, and empirical analysis was conducted to determine the differences of Henan construction industry in the period of 2012-2018 in the aspect of carbon emission efficiency. Results showed that the total-factor carbon emission efficiency of Henan construction industry in the period of $2012-2018$ was $1.084 \%$, which indicated a certain increase in the total-factor emission efficiency of Henan construction industry over the 7 years. The overall resource utilization efficiency of Henan construction industry was improved by $0.84 \%$ due to the joint actions of elevated technological progress (by $0.35 \%$ ) and improved technical efficiency (by $0.47 \%$ ). Average pure technical efficiency was slightly reduced by $0.03 \%$, which indicated that building scale was the driving force for improving the total-factor efficiency of the construction industry. The study results can provide systematic and comprehensive carbon emission information in the construction industry for policy making. Therefore, the carbon emission status of the construction industry in one province can be mastered from a provincial level to clarify responsibilities, facilitate coordinated development, and boost the efficiency and equity of emission reduction in the construction industry. This way will be important for finally realizing the goals of energy conservation, emission reduction, and low-carbon development.
\end{abstract}

\section{INTRODUCTION}

The rapid growth of China's economy in the past nearly 40 years has stimulated massive energy consumption and ever-growing carbon emission. China is a developing country with an enormous population base and a country with the greatest energy consumption and the highest carbon emission. Therefore, with the high-speed development of urbanization, the Chinese construction industry is consuming a large quantity of resources and energy, generating massive carbon emission, and posing challenges to sustainable development while making great contributions to national economic development. Therefore, this industry shoulders heavy reasonability for carbon emission reduction. Chinese buildings belong to buildings with high energy consumption and enormous every-saving potential, and the energy conservation and transformation of buildings should be given close attention. Different from developed countries, China is faced with the rapid growth of energy consumption and carbon emission of the construction industry induced by large-scale construction projects in the current urbanization progress in addition to enormous energy consumption and carbon emission in the daily operation of buildings. Thus, the construction industry is important to the overall consumption of natural resources and carbon emission. The scale of the Chinese construction industry, which is an industry with the most concentrated energy consumption and carbon emission, accounts for half of the global construction industry. Cement and steel materials used in buildings occupy approximately half of global consumption. Thus, the energy conservation and emission reduction of the construction industry are imperative and especially important to understand and analyze the energy consumption and carbon emission in the total industrial chain of the Chinese construction industry using the idea of the life cycle. 
Henan Province, China is a province undergoing typical severe environmental pollution induced by the construction industry. Fig. 1 shows that the house construction area in Henan construction industry was $245,960,000 \mathrm{~m}^{2}$ in 2009 , but this figure rapidly rose to $637,890,000 \mathrm{~m}^{2}$ up to 2018 with the rapid population growth and economic development, and the annual average growth rate reached as high as $17.7 \%$. This situation has fully verified the rapid growth of energy consumption and carbon emission triggered by large-scale construction projects in the construction industry during the urbanization progress in Henan Province. In recent years, Henan construction industry has still presented high energy consumption and severe environmental pollution. Henan Province was taken as an example in this study to measure carbon emission efficiency of its construction industry and its measures for minimization of environmental pollution to perfect the evaluation of pollutant discharge in the construction industry and finally reach the effect of environmental improvement by implementing the concepts of sustainable development and green buildings.

\section{PAST STUDIES}

Among abundant studies on carbon emission of the construction industry, most have concentrated on carbon emission in the construction product life cycle, calculation of total carbon emission in the construction industry, and carbon emission factor and activity level of the construction industry. Carbon emission efficiency is a current environmental problem and a major research topic. Carbon emission, which is the most significant environmental impact, is usually used to characterize the degree of environmental impact, and carbon emission efficiency in the construction industry is also an important content in current environmental pollution of the construction industry. Works related to the carbon emission of the construction industry are discussed as follows. Suzuki et al. used the classified input-output table of basic Japanese departments to quantify carbon emissions generated by all kinds of house buildings (Suzuki et al. 1995). Mielnik et al. proposed the "carbonization index," which was extensively applied to studies on carbon emission in the construction industry as a useful index used to evaluate evolution patterns of climatic changes in industrialized and developing countries (Mielnik et al. 1999). Acquaye et al. calculated energy and greenhouse gas emission intensities of Irish construction sector and subsector, estimated their contributions to nationwide emission in Ireland and analyzed the influence of the construction industry on carbon emission (Acquaye et al. 2010). Chang et al. constructed an input-output life cycle assessment model of the construction industry based on the economic benchmarks of China in 2002, 2005, and 2007. The results showed that the embodied energy of Chinese construction projects accounted for 25\%-30\% of the total energy consumption, the emission of embodied $\mathrm{SO}_{2}$ was controlled, and the emission intensity of embodied $\mathrm{NOx}$ and $\mathrm{CO}_{2}$ was reduced (Chang et al. 2011). Zuo et al. considered that China was one of the countries with the largest energy consumption and carbon emission in the world, held a semi-structured interview with people occupied in the construction industry and determined the influencing factors of the construction industry to realize low carbonization. The results indicated that market demand, material selection, knowledge of facility manager, and governmental support and leadership were critical influencing factors of the low-carbon development of the construction industry (Zuo et al. 2012). Jeong et al. quantified $\mathrm{CO}_{2}$ emissions generated by primary building materials, which were consumed in the construction process of six apartments with different sizes in Korea. The results were of certain reference value to the sustainable design of residential complexes and could serve

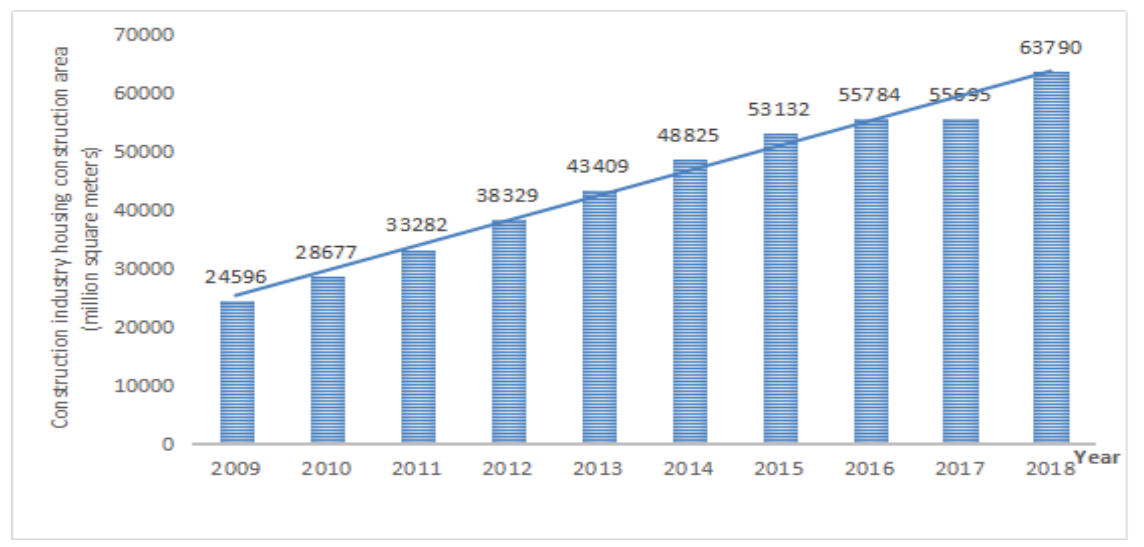

Fig. 1: House construction areas (ten thousand square meters) in Henan construction industry in the period of 2009-2018. 
as technical measures for $\mathrm{CO}_{2}$ emission reduction in the construction industry (Jeong et al. 2012). Li et al. analyzed the influence of embodied carbon of residential buildings in China, evaluated the influence of concrete carbon by taking three types of residential buildings in China as an example, and introduced concrete carbon emission measures for the construction industry ( $\mathrm{Li}$ et al. 2014). Onat et al. quantified carbon footprints of American houses and commercial buildings and calculated carbon emissions in construction, use, and disposal phases in the base year 2002. The results showed that the emission was the highest in the use phase of the construction industry and accounted for $91 \%$ of the total emission in the total life cycle phase of American buildings (Onat et al. 2014). Feng et al. used panel data of 30 provinces in the period of 2004-2011 to conduct an empirical study of the total-factor energy efficiency of the interprovincial construction industry in China. The results indicated that the construction industries in different provinces had evident differences in energy efficiency and $\mathrm{CO}_{2}$ emission, and scale of the construction industry, population density, liquidity of building materials, and urbanization rate were important influencing factors of interprovincial $\mathrm{CO}_{2}$ emission differences (Feng et al. 2014). Xue et al. used the DEA (Data Envelopment Analysis)-based Malmquist productivity index (MPI) to conduct an empirical study on the changes in energy consumption and productivity of the construction industries in 26 provinces in China in the period of 2004-2009. The findings showed that the construction industries in northeast, west, central, and east regions in China had different energy conservation conditions, and carbon accounting could help decision-makers improve sustainable development strategies for the Chinese construction industry (Xue et al. 2015). Hong et al. used a multi-regional input-output model to investigate the energy consumption status in the Chinese construction industry. The results showed that the total coal consumption of the construction industry, which is a typical demand-driven industry, was 793,740,000 tons in 2007 and accounted for $29.6 \%$ of the total energy consumption in China. This study provided a basis for formulating and implementing policies used to reduce energy use and reduce carbon emission in the construction industry (Hong et al. 2016). Lu et al. evaluated the effectiveness of emission policies of Chinese buildings and calculated carbon emissions of the Chinese construction industry from 1994 to 2012. The results showed that the annual average emission of the Chinese construction industry grew by $6.9 \%$ between 1994 and 2012, and "consumption of building materials" had the greatest contribution to the growth of total carbon emission. This study provided a new scientific basis for carbon emission in the Chinese construction industry ( $\mathrm{Lu}$ et al. 2016). Zhang et al. used the data of the construction industries in 30 provinces in Mainland China from 2005 to 2016 to conduct an empirical study of their carbon emission efficiency. The results manifested that effective popularization of low-carbon construction technologies and market-oriented reform of state-owned construction enterprises must be conducted to improve the development level of the Chinese construction industry (Zhang et al. 2019). The existing studies show that international incentive policies and control standards for accounting method of building carbon emission and low-carbon building development are quite mature and complete. By contrast, Chinese low-carbon buildings have a late start, and related supporting systems, such as financial and tax incentive policies and evaluation criteria specific to evaluation market of low-carbon buildings, are still incomplete. Most works on the evaluation system of low-carbon buildings are qualitative, while quantitative studies are insufficient, which radically restricts the construction and implementation of the evaluation system of Chinese low-carbon buildings. A few scholars have explored the complete carbon emission of the overall Chinese construction industry, but the emission condition and features of the construction industry in one province remain unclear. Thus, understanding and analysing the current carbon emission status and the tendency of the Chinese construction industry are important. Therefore, Henan Province, China, was taken as an example in this study. By calculating the overall carbon emission efficiency of Henan construction industry and establishing the evaluation framework for its carbon emission efficiency, the differences among various cities in carbon emission efficiency of the construction industry and the historical variation trends of carbon emission efficiency in various regions were compared. The coordinated development conditions between the construction industry and environmental carbon emission reduction in these regions were also analyzed. The contributing factors of the improvement in efficiency level were identified as well.

\section{MODEL INTRODUCTION AND DATA DESCRIPTION}

\section{Introduction of DEA-Malmquist Model}

Charnes et al. (1978) proposed the DEA-CCR (Charnes, Cooper, Rhodes) model at the earliest. Its principle is that the input or output of decision-making units (DMUs) is kept unchanged, and relatively effective production frontier is determined using statistical data through mathematical programming method. This model as a method of constructing nonparametric frontier can clearly define comparison benchmarks without the need to hypothesize the measurement function or requiring any preset condition. This 
method evaluates the relative effectiveness of each DMU by comparing the degree of deviation after projecting DMUs onto the frontier. It has been gradually applied to evaluate production performance.

Given $n$ DMUs with each DMU having $m$ input variables and s output variables, the input and output variables of the $\mathrm{j}($ th) DMU are defined as follows:

$$
\begin{aligned}
& X_{j}=\left(x_{1 j}, x_{2 j}, \cdots, x_{m j}\right)^{T}>0 \\
& Y_{j}=\left(y_{1 j}, y_{2 j}, \cdots, y_{m j}\right)^{T}>0 \\
& j=1,2,3, \cdots, n
\end{aligned}
$$

A solution, as shown in Formula (2), is established by programming.

$$
\text { s.t. }\left\{\begin{array}{l}
\theta \sum_{n j=1}^{n} \lambda_{j} x_{i j}+s^{-}=\theta x_{0}, i=1,2, \cdots 3 m \\
\sum_{j=1}^{n=1} \lambda_{j} y_{i j}-s^{+}=y_{0}, i=1,2,3, \cdots, s \\
s^{-}, s^{+}, \lambda_{j} \geq 0, j=1,2,3, \cdots, n
\end{array}\right.
$$

Where, $x_{i j}$ and $y_{i j}$ are the input and output variables of DMU, respectively; $x_{0}$ and $y_{0}$ are the target input and output values, respectively; $\theta$ is a parametric variable; $s^{-}$and $s^{+}$are the slack variables of input and output, respectively; $\lambda_{j}$ is the weight coefficient of each input and output variables. DEA-CCR model assumes constant returns to scale (CRS) of DMU. Banker et al. (1992) made some improvements based on this model because of the difficulty in realizing the above-mentioned assumption. Under variable returns to scale (VRS), constraint condition $\sum \lambda_{j}=1$ is added, and DEA-BCC model is obtained.

DEA-Malmquist model generates a production possibility set $\mathrm{S}_{t}$ for all feasible inputs and outputs in the period $t$, and the distance function of production possibility set in period $\mathrm{D}^{t}$ is defined as:

$$
D^{t}\left(x_{0}^{t}, y_{0}^{t}\right)=\inf \left(\theta \mid\left(x_{0}^{t}, y_{0}^{t} / \theta\right)\right.
$$

The calculation method of Malmquist performance change index (MPCI) is shown in Formula (4).

$$
\operatorname{MPCI}_{t}^{t+1}=\left(\frac{D_{C R S}^{t}\left(x_{0}^{t+1}, y_{0}^{t+1}\right)}{D_{C R S}^{t}\left(x_{0}^{t}, y_{0}^{t}\right)} \bullet \frac{D_{C R S}^{t+1}\left(x_{0}^{t+1}, y_{0}^{t+1}\right)}{D_{C R S}^{t+1}\left(x_{0}^{t}, y_{0}^{t}\right)}\right)^{1 / 2}
$$

MPCI can be decomposed into pure technical efficiency change index (PTECI), scale efficiency change index (SECI), and technological change index (TCI) to present more valuable analytical information, as shown in Formula (5).

$$
\operatorname{MPCI}_{t}^{t+1}=\mathrm{PTECI}_{t}^{t+1} \times \operatorname{SECI}_{t}^{t+1} \times \mathrm{TCI}_{t}^{t+1}
$$

Where $\operatorname{PTECI}_{t}^{t+1}=\frac{D_{V R S}^{t+1}\left(x_{0}^{t+1}, y_{0}^{t+1}\right)}{D_{V R S}^{t}\left(x_{0}^{t}, y_{0}^{t}\right)}$,

$S E C I_{t}^{t+1}=\frac{D_{C R S}^{t+1}\left(x_{0}^{t+1}, y_{0}^{t+1}\right) / D_{V R S}^{t+1}\left(x_{0}^{t+1}, y_{0}^{t+1}\right)}{D_{C R S}^{t+1}\left(x_{0}^{t}, y_{0}^{t}\right) / D_{V R S}^{t+1}\left(x_{0}^{t}, y_{0}^{t}\right)}$, and

$$
T C I_{t}^{t+1}=\left(\frac{D_{C R S}^{t}\left(x_{0}^{t+1}, y_{0}^{t+1}\right)}{D_{C R S}^{t+1}\left(x_{0}^{t+1}, y_{0}^{t+1}\right)} \bullet \frac{D_{C R S}^{t}\left(x_{0}^{t}, y_{0}^{t}\right)}{D_{C R S}^{t+1}\left(x_{0}^{t}, y_{0}^{t}\right)}\right)^{1 / 2} \cdot \mathrm{CRS} \text { and VRS }
$$

denote constant returns to scale and variable returns to scale.

\section{Data Description}

Most studies on the total-factor production efficiency of the construction industry have investigated from two aspects: input and output. The existing works have neglected unexpected environmental output while considering production factors. $\mathrm{CO}_{2}$ emission obtained through the process analysis method was taken as an input index, namely, environmental input, to investigate the total-factor emission efficiency of the construction industry in each prefecture-level city in Henan Province.

Environmental input: Total carbon emission environment variable of the construction industry was selected as the input index. On the one hand, environmental impact can be regarded as a price of economic development; on the other hand, carbon emission permit is gradually commercialized, is equivalent to the cost to be paid by enterprises during their production process, and can influence production as a production factor. Here, carbon emission, which is an unexpected environmental output, was turned into an input variable.

Labour input: The construction industry is a labour-intensive industry. The development degree and competitiveness of this industry rely on labour quantity and quality to a great extent. Here, the annual average number of people directly occupied in production and management was selected as labour input index.

Capital input: Expanding the extension for reproduction is the main development pattern of Henan construction industry, where capital input is an important driving force for the economic growth of the construction industry. The fixed asset was used as capital input index in this study, the average value of fixed assets at the end of the last year and those at the end of the year was taken as the annual input value of fixed assets, and the values were uniformly converted into the constant price in 2012 using GDP (Gross Domestic Product) deflator to eliminate the influence of price change factor.

The input of construction machinery equipment: Henan construction industry relies on the artificial or semi-artificial operation to a great extent. The improvement of construction mechanization level can facilitate the production efficiency of the construction industry, the total power of construction machinery equipment of the construction industry in each region can represent its input level of 
construction machinery equipment, and the annual index value is the average value of total power of construction machinery equipment at the end of the last year and that at the end of the year.

Output index: For consistency of evaluation scope, the total output value of the constant price of the construction industry in each prefecture-level city in Henan Province was taken as input index in this study.

The above-mentioned used total output value, construction area, completion area, average number of people directly occupied in production and management, fixed assets and total power of construction machinery equipment of the construction industry in each province over the years were all derived from China Statistical Yearbook of Construction over the years. Total output value was converted into the constant price in 2012 using annual GDP deflator in the construction industry. All data in this study were related data of 17 prefecture-level cities in Henan Province from 2012 to 2018.

\section{RESULT ANALYSIS}

Panel data of 17 prefecture-level cities in Henan Province in the period of 2012-2018, as given in Table 1, were calculated via Deap2.1 software package.

Table 1 shows that the total-factor carbon emission efficiency of Henan construction industry in the period of 2012-2018 was 1.084 , which was greater than 1 . This finding indicated that the total-factor carbon emission efficiency of Henan construction industry was elevated to a certain degree during the 7 years. The Malmquist index decomposition results showed that the mean values of technical efficiency and technological progress were 1.047 and 1.035 , respectively. This result implied that the overall resource utilization efficiency of Henan construction industry was improved by $0.84 \%$ due to the joint actions of elevated technological progress (by $0.35 \%$ ) and improved technical efficiency (by $0.47 \%$ ). Various regions in Henan Province promoted the movement of production frontier by enhancing technological innovation and elevating the overall production level in the construction industry to realize optimal allocation of production factors brought by progress of the construction industry and improve the efficiency. In the construction industry of each region, the previous production pattern of "emphasized quantity while neglecting quality" was gradually changed. Moreover, technological innovation would become a critical factor in enhancing industrial competitiveness. The average value of pure technical efficiency of Henan construction industry was slightly reduced by $0.03 \%$, and the change in pure technical efficiency reflected whether the construction industry in each city in Henan Province could effectively use production technology to maximize the output. The construction industries in most regions failed to rapidly keep up with innovation to improve R\&D quality because of low carbon emission efficiency due to ineffective overall production organization strategy and poor management ability of Henan construction industry. This situation, from another aspect, explained Henan Province had a space for continuous improvement in optimizing management mode of the construction industry, popularizing energy conservation and emission reduction technology, and rapidly following the industrial development. The average value of scale efficiency was improved by $0.51 \%$, which was very obvious. This finding fully certified that Henan construction industry realized scale growth between 2012 and 2018. Scale efficiency reflected that Henan construction industry was at a proper investment scale, which manifested that the construction industries in most regions of Henan Province kept a slow growth trend, and effective scale expansion was the driving force for improving their total-factor efficiency.

\section{CARBON EMISSION REDUCTION MEASURES OF THE CONSTRUCTION INDUSTRY}

\section{Advocating Application of Low-Carbon Energy in Buildings and Lengthening Service Life of Buildings}

The energy structure in the use phase of most buildings in

Table 1: Total-factor carbon emission efficiency of Henan construction industry in the period of 2012-2018.

\begin{tabular}{|llllll|}
\hline Year & Technical efficiency & Technological progress & Pure technical efficiency & Scale efficiency & Total-factor productivity \\
\hline $2012-2013$ & 0.867 & 0.986 & 1.002 & 0.865 & 0.855 \\
$2013-2014$ & 0.967 & 0.865 & 0.987 & 0.980 & 0.836 \\
$2014-2015$ & 1.034 & 1.023 & 0.934 & 1.107 & 0.938 \\
$2015-2016$ & 1.024 & 1.086 & 1.092 & 1.234 & 1.058 \\
$2016-2017$ & 1.176 & 1.154 & 0.953 & 1.200 & 1.357 \\
$2017-2018$ & 1.214 & 1.098 & 1.012 & 1.051 & 1.333 \\
Average value & 1.047 & 1.035 & 0.997 & & 1.084 \\
\hline
\end{tabular}


Henan Province now mainly concentrates on electric energy. The carbon emission factor of electric energy is far higher than those of other energy sources, and the carbon emission in the use phase is far higher than those in other phases. On the one hand, the carbon emission of electric energy is high because electric energy belongs to the secondary energy source, and a certain energy loss will be generated in the transformation or processing process of primary energy sources. On the other hand, coal and fuel oil are energy sources with high carbon emission given that the current electric energy has an extreme dependence on them. Therefore, the energy structure of public buildings should be changed, low-emission clean energies, such as solar energy, wind energy, and ocean energy should be energetically developed, and high-efficiency, clean, and low-carbon power supply technology and power supply system should be popularized to reduce the carbon emission factor of electric energy and reduce carbon emission in the use phase. Transformation and reinforcement measures should be taken to lengthen the structural lifetime of buildings, improve their use functions and functional quality, and lengthen their service life to promote their sustainable development.

\section{Conducting Reasonable and Scientific Building Construction and Reducing Carbon Emission in the Building Construction Link}

By scientifically formulating construction organization and dismantling schemes, materials and personnel transportation can be reduced within the scientific and feasible scope and the operations in the construction process can be simplified. Energy-saving construction machinery equipment should be selected as far as possible to realize optimization of use efficiency of machinery and reduce carbon emission in the construction process. Two defects exist in night-time construction, namely, low construction efficiency and demand for a large quantity of temporary lighting. These defects will not only consume massive electricity but also increase construction-induced carbon emission. Therefore, actual construction technological characteristics should be combined to reasonably arrange construction and demolition time, shorten night-time operation hours, and reduce carbon emission. The specific demolition process should be clarified when the construction method is determined. Reasonable demolition equipment should be confirmed. The use of cranes and equipment that may damage the buildings should be reduced to decrease carbon emission in the demolition phase. The government should perfect low-carbon technical indexes and requirements of demolition engineering and reduce carbon emission in building demolition under the constraints of compulsory standards.

\section{Strengthening the Propaganda of Low-Carbon Use of Buildings and Encouraging Low-Carbon Construction Projects}

We need to comprehensively popularize the concepts of energy conservation, emission reduction, and low carbon from two angles, namely, professionalism and territoriality, for popularizing the carbon trading-based economic evaluation model for carbon emission of public buildings. Universal education among the public should be generalized. The government and construction industry should propagandize the calculation of potential benefits of low-carbon public buildings by formulating policies and implementing standards, media publicity, and compulsory education to ensure that the public can be aware of the existence of the potential benefits. This way provides the market basis for low-carbon public buildings. Professional education in the building field should be reinforced. The government can create a good environment and conditions for energy conservation and emission reduction market by promoting policies and guiding the market. Meanwhile, real estate enterprises have advantages in capital, technology, and talent. Advantages of the two can be combined to push a series of low-carbon public building products recognized by the market at various pilot areas, create a thick atmosphere of carbon trading, and publicize economic benefits of low-carbon public buildings. In this way, investors can be aware of the real values of low-carbon public buildings. Their enthusiasm for developing low-carbon buildings will be motivated to enhance their decision-making tendency toward investing in low-carbon public buildings.

\section{Stimulating Related Interest Subjects to Participate in Emission Reduction and Reinforcing Technological Innovation of the Construction Industry}

The government should exert its role of policy promotion and guiding, stimulate interesting interest subjects involved in the development of low-carbon public buildings, and fully motivate related subjects' initiative in participating in low-carbon development of public buildings. Moreover, the government should give subsidies to electric energy saved by public buildings with good energy operation and management, stimulate investors to enter the low-carbon field of public buildings, encourage related subjects to be occupied in development of new-type energy, emission reduction technology, equipment, and products in the form of scientific research funds, reduce the development cost of enterprises' low-carbon technologies, and provide financial support and subsidies, such as loans, for subjects using and popularizing low-carbon technologies. The subjects should do heat insulation work of building envelopes and improve the efficiency 
of heating, HVAC (Heating, Ventilation and Air Conditioning), and lighting equipment and system and create a natural ecological environment for buildings. They should also popularize building sun-shading technology, solar water heater technology, and passive solar house technology. They should manage natural ventilation and natural lighting very well and advocate roof greening as well. Furthermore, they should continuously perfect energy-saving industrial structure of buildings, promote comprehensive upgrading of various energy-saving construction industries, and gradually form a complete range of modernized energy-saving construction industry system with advanced technologies and standard management.

\section{CONCLUSION}

Construction products manufactured by construction activities, which are basic human behaviours of nature remaking, are the main consumers of resources and energy sources and also main dischargers causing environmental pollution. The pressure imposed by the construction industry on resources and the environment is increasing daily. With accelerated China's urbanization progress, the energy consumption and carbon emission of the building field are increasing, and reducing environmental pollution of the construction industry while ensuring its sustainable development is especially critical. Improving the total-factor carbon emission efficiency of the construction industry is a primary measure. This study constructed a carbon emission efficiency model that took carbon emission as an environmental factor and calculated carbon emission efficiency of Henan construction industry in the period of 2012-2018. The study results indicated that the total-factor carbon emission efficiency of Henan construction industry was 1.084 from 2012 to 2018 , and the elevated $0.84 \%$ part was derived from $0.35 \%$ elevation of technological progress and $0.47 \%$ improvement of technical efficiency. The average value of pure technical efficiency was slightly reduced by $0.03 \%$, while that of scale efficiency was elevated by $0.51 \%$. The carbon emission efficiency of the construction industry could be improved by advocating the use of low-carbon energy sources in buildings, reasonably and scientifically organizing building construction, reinforcing propaganda of low-carbon use of buildings, and motivating related interest subjects to participate in the emission reduction of the construction industry to reduce environmental pollution caused by the construction industry. In-depth research is suggested from the aspects of perfecting life cycle assessment method for carbon emission calculation of the construction industry, analysing the influence paths of associated industries on carbon emission of the construction industry, deeply probing into the environmental impact of the construction industry and its structure, and comprehensively considering all kinds of environmental impacts of the construction industry.

\section{ACKNOWLEDGEMENT}

This work was supported by the Key Scientific Research Projects of Colleges and Universities in He nan Province (18A560019, 20B560013).

\section{REFERENCES}

Acquaye, A.A. and Duffy, A.P. 2010. Input-output analysis of Irish construction sector greenhouse gas emissions. Building and Environment, 45(3): 784-791.

Banker, R.D. and Thrall, R.M. 1992. Estimation of returns to scale using data envelopment analysis. European Journal of Operational Research, 62(1): 74-84.

Charnes, A., Cooper, W.W. and Rhodes, E. 1978. Measuring the efficiency of decision making units. European Journal of Operational Research, 2(6): 429-444.

Chang, Y., Ries, R.J. and Wang, Y. 2011. The quantification of the embodied impacts of construction projects on energy, environment, and society based on I-O LCA. Energy Policy, 39(10): 6321-6330.

Feng, B., Wang, X. and Liu, B. 2014. Provincial variation in energy efficiency across China's construction industry with carbon emission considered. Resources Science, 36(6): 1256-1266.

Hong, J., Shen, G.Q., Guo, S., Xue, F. and Zheng, W. 2016. Energy use embodied in China' s construction industry: a multi-regional input-output analysis. Renewable and Sustainable Energy Reviews, 53: 1303-1312.

Jeong, Y.S., Lee, S.E. and Huh, J.H. 2012. Estimation of $\mathrm{CO}_{2}$ emission of apartment buildings due to major construction materials in the Republic of Korea. Energy and Buildings, 49: 437-442.

Li, X., Yang, F., Zhu, Y. and Gao, Y. 2014. An assessment framework for analysing the embodied carbon impacts of residential buildings in China. Energy and Buildings, 85: 400-409.

Lu, Y., Cui, P. and Li, D. 2016. Carbon emissions and policies in China's building and construction industry: evidence from 1994 to 2012. Building and Environment, 95: 94-103.

Mielnik, O. and Goldemberg, J. 1999. Communication The evolution of the "carbonization index" in developing countries. Energy Policy, 27(5): 307-308.

Onat, N.C., Kucukvar, M. and Tatari, O. 2014. Scope-based carbon footprint analysis of US residential and commercial buildings: An input-output hybrid life cycle assessment approach. Building and Environment, 72: 53-62.

Suzuki, M., Oka, T. and Okada, K. 1995. The estimation of energy consumption and $\mathrm{CO}_{2}$ emission due to housing construction in Japan. Energy and Buildings, 22(2): 165-169.

Xue, X., Wu, H., Zhang, X., Dai, J. and Su, C. 2015. Measuring energy consumption efficiency of the construction industry: the case of China. Journal of Cleaner Production, 107: 509-515.

Zuo, J., Read, B., Pullen, S. and Shi, Q. 2012. Achieving carbon neutrality in commercial building developments-Perceptions of the construction industry. Habitat International, 36(2): 278-286.

Zhang, P., Jia, G., Mou, Q., Song, M., He, C. and Xu, Q. 2019. Carbon productivity convergence club and its initial conditions: China's construction industry. Chinese Journal of Population Resources and Environment, 17(1): 12-24. 